NBER WORKING PAPER SERIES

INFLATION AND LABOR-MARKET ADJUSTMENT

Daniel S. Hamernesh

Working Paper No. 1153

NATIONAL BUREAU OF ECONOMIC RESEARCH

1050 Massachusetts Avenue

Cambridge MA 02138

June 1983

Professor of Economics, Michigan State Unversity, and Research Associate, National Bureau of Economic Research. Support for this research was provided by the Alfred P. Sloan Foundation. Helpful comments were provided by James Brown, John Carlson, James Johannes, Lawrence Kahn, and participants in seminars at the NBER, Guelph, Iowa, Michigan State and Minnesota. The research reported here is part of the NBER's research program in Labor Studies. Any opinions expressed are those of the author and not those of the National Bureau of Economic Research. 


\section{INFLATION AND LABOR-MARKET ADJUSTMENT}

\section{$\underline{\text { ABSTRACT }}$}

The implications of downward nominal and ex ante real wage rigidity, and of wage contracting for the dispersion of relative wage changes in the presence of price inflation are examined. Rigidity implies that unexpected inflation will raise the variability of relative wage changes; contracting implies unexpected inflation reduces variability. Using data on manufacturing industries for 1955-81, and on private nonfarm industries for 1965-81, these hypotheses are studied. The dispersion in relative wage changes is reduced by greater price inflation. Most of the reduction is a response to unexpected inflation: Expected inflation has little impact on dispersion. These findings hold for subperiods within the sample, and are robust to different choices of measures of price expectations, including those of the Livingston survey, the Survey Research Center household data, and ARMA forecasts. They stand in striking contrast to the commonly accepted result that price inflation is associated with greater dispersion of relative price changes. They suggest that inflation reduces the ability of relative wages to signal disequilibria among labor markets.

Daniel S. Hamermesh Dept. of Economics Marshall Hall Michigan State University East Lansing, MI 48824 


\section{Introduction}

A vast array of studies has examined how the labor market affects inflation. In this study I reverse the process and examine how inflation affects adjustment in labor markets. Similarly, a rapidly growing literature has shown that inflation raises the variability of relative price changes, and has interpreted this finding as demonstrating the effects of inflation on the allocative efficiency of the market mechanism. (See Vining-Elwertowski, 1976; Parks, 1978; Fischer, 1982; and CukiermanWachtel, 1982.) The major empirical focus of this study is an examination of how inflation affects the variability of relative wage changes. With rare exceptions (Altonji, 1982, and Brown, 1982, are the best examples) modern theories of macroeconomic adjustment have not been tested on the labor market; where they have, the examination has been restricted to aggregate wage inflation or employment determination. So too, atheoretical empirical studies of cyclical variation in inequality in wage levels are legion (most recently, Wachter, 1970); and one study (Ashenfelter-Layard, 1983) correlated wage inflation with inequality in the rate of wage increases. None has made a study of the determinants of inequality in relative wage changes comparable to the studies of relative price changes, and none has used empirical work on inequality in rates of wage changes to examine the validity of theories of macroeconomic adjustment.

In Section II I outline how changes in the rate of price inflation affect relative wage adjustment under two alternative theories of the determination of relative wage changes. The first is a simple Keynesian notion of downward wage rigidity; the second is based on notions of wage contracting. The implications of these adjustment mechanisms for the effects of inflation on inequality of relative wage changes are drawn out. 
In Section III, I test the implications for inequality of relative wage changes on two different data sets. In addition to providing evidence on the validity of these theories, the tests provide a new, strongly-supported fact describing the adjustment of labor markets. This result stands, moreover, in surprising contrast to results others have obtained on the effects of price inflation on the distribution of relative price changes.

II. Theories of Adjustment and Relative Wages

Throughout this section I base the discussion on a standard model of wage determination:

$$
w_{i}=p^{e}+\gamma p^{u}+\alpha y_{i},
$$

where $i$ is an economic subunit; $w$ is the instantaneous rate of wage increase; $\mathrm{p}^{\mathrm{e}}$ and $\mathrm{p}$ are the instantaneous rates of expected and unexpected aggregate price inflation; $y_{i}$ is the nominal rate of change of excess demand in the $i$ 'th sector, deflated by $p$; and $\alpha$ and $\gamma$ are parameters, $\gamma \leq 1$. This general model can be modified to analyze the effects of alternative assumptions about wage determination.

A. A Simple Keynesian Assumption

Perhaps the essence of Keynesian adjustment is the assumption of downward nominal wage rigidity. How does price inflation affect adjustment in the labor market under this assumption? Rees (1970) has claimed, "A gently rising price level will lubricate relative price changes...." Tobin (1972) argues that inflation is beneficial in improving matches between workers and jobs. These views are consistent with the casual observation that inflation enables firms to provide real rewards to those whose productivity is increasing while cutting real rewards to those who are becoming less productive without reducing their nominal wages. We modify (1) by assuming further that $\mathrm{y}$ is a random variable with some distribution function, $G(y)$, and density function, $g(y)$, and that: 


$$
w_{i}=\max \left[p^{e}+\gamma p^{u}+\alpha y_{i}, 0\right] .
$$

This modification means that wage increases are either $p^{e}+\gamma p^{u}+\alpha y_{i}$ or zero, with $w_{i}=0$ if $y_{i}<-\left(p^{e}+\gamma p^{u}\right) / \alpha=y^{*}$. The average wage increase in the economy is then:

$$
w=\int_{y^{*}}^{\infty}\left[p^{e}+\gamma p^{u}+\alpha y\right] g(y) d y=\left[1-G\left(y^{*}\right)\right] A+\alpha \int_{y}^{\infty} y g(y) d y,
$$

where $A=p^{e}+\gamma p^{u}$.

The variance in the rate of increase in money wages across subunits is :

$$
\operatorname{Var} w_{i}=\int_{y *}^{\infty}[A+\alpha y-w]^{2}(y) d y+w^{2} G\left(y^{*}\right) .
$$

Letting $\alpha=1$ temporarily to simplify the arithmetic, and differentiating in (4) with respect to $A$, one can show that:

$$
\partial \operatorname{Var} w_{i} / \partial A=2 G\left(y^{*}\right)\left[1-G\left(y^{*}\right)\right] w^{*},
$$

where $w^{*}$ is the mean increase in those subunits with positive (nonzero) wage changes. Since $A$ increases with both $\mathrm{p}^{\mathrm{e}}$ and $\mathrm{p}^{\mathrm{u}}$, the variance of money wage changes will be increased as price inflation mitigates the effect of nominal wage rigidity. Moreover, the effect of expected price inflation will be greater than that of unexpected price inflation, for $\partial A / \partial p^{e}>\partial A / \partial p^{u}>0$. If inflation does make labor markets work more efficiently by allowing the effects of variations in $y_{i}$ to be reflected in wage changes, we should observe a positive relation between the variance in wage changes and the rate of price inflation. This positive relation will be greater for expected than for unexpected inflation.

One might argue that the form of rigidity in (2) characterized well a world in which inflation was rare, but is a poor characterization of a world in which price changes are generally positive. One might modify (2) by replacing the zero with $\mathrm{p}^{\mathrm{e}}$; this respecification implies that all workers receive a wage increase at least equal to the expected rate of price inflation. 
Though hardly a Keynesian assumption it is in accord with notions of real wage rigidity (though it implies ex ante rather than ex post aggregate real wage rigidity). I/ Under such a modification of (2) the conclusion about the effect of expected price inflation on the variance of wage changes is altered. Expected price inflation has no effect on the variance of wage increases across economic units (since all workers receive at least $\mathrm{p}^{\mathrm{e}}$, and changes in $p^{e}$ do not affect the fraction of workers whose wage increases are constrained to be no greater than $p^{e}$ ). However, as before, increases in $p^{u}$ raise the fraction of workers whose wage changes exceed $p^{e}$; thus unexpected inflation increases the variance of changes in relative wages.

Both specifications imply that price inflation will affect the ability of relative wages to allocate labor among firms. In the specification embodied in (2) both unexpected and expected price inflation increase the effects of differences in excess demand among firms on differences in wage changes. To the extent flows of labor respond to relative wage changes, more rapid inflation will "lubricate" the market, causing both output and employment to be greater. Ex ante real wage rigidity will obviate the beneficial effect of expected inflation on relative wages, and thus on allocation of labor; but more rapid unexpected inflation will still improve the allocation of labor through its effects on relative wage changes.

C. A Contracting Approach

Stated very succinctly, an increase in wage contracting--an increased reliance upon ex post changes in price inflation in setting wages--alters (1) by increasing $\gamma$ and reducing $\alpha$. In the extreme case of complete indexing with industry conditions not affecting wage determination at a11, $\gamma=1$ and $\alpha=0$. Assuming that greater uncertainty, denoted by $u$, affects these wage-setting parameters in this manner, (1) can be rewritten: 
$\left(1^{\prime}\right) w_{i}=p^{e}+\gamma(u) p^{u}+\alpha(u) y_{i}, \gamma^{\prime}>0, \alpha^{\prime}<0$

Taking variances across industries in ( $\left.1^{\prime}\right)$ :

(5) $\operatorname{Var} \mathrm{w}_{i}=[\alpha(\mathrm{u})]^{2} \operatorname{Var} \mathrm{y}_{i}$.

Taking logarithms in (5) and linearizing:

(6) $\log \left(\operatorname{Var} \mathrm{w}_{i}\right)=\log \left(\operatorname{Var} \mathrm{y}_{i}\right)+\alpha_{0}-\alpha_{1} \mathrm{u}$.

This derivation is, unfortunately, completely mechanical. The reason why $\gamma>0$ is given by Gray (1978), who shows that increased uncertainty about inflation makes more indexing optimal. The other part of the issue is why optimizing agents might choose to rely more on wage indexation and less on the vicissitudes of the market for goods or seryices they are producing. One can rationalize this by considering the worker in a typical industry who must purchase a market basket of goods, the price of which is increasing at a rate $p$, but whose wage, according to (1), is part1y determined by $y_{i}$. Let the average perceived correlation between $p$ and $y_{i}$ be denoted by $r_{0}$. At the uncertainty denoted by this correlation, the average worker will supply labor to the average industry for combinations of indexed wages and a risk premium, contingent upon $y_{i}$, no worse than those combinations shown by the frontier $\mathrm{U}_{\mathrm{r}_{0}}$ in Figure 1 . The frontier slopes down because workers require a greater risk premium to forgo indexation; it is convex because, the less security workers derive from indexation, the greater the incremental risk premium required to leave the workers no worse off.

In competitive product markets employers must offer workers a combination of indexation and risk premiums along $\mathrm{U}_{\mathbf{r}_{0}}$. For the typical 
Wage Indexing

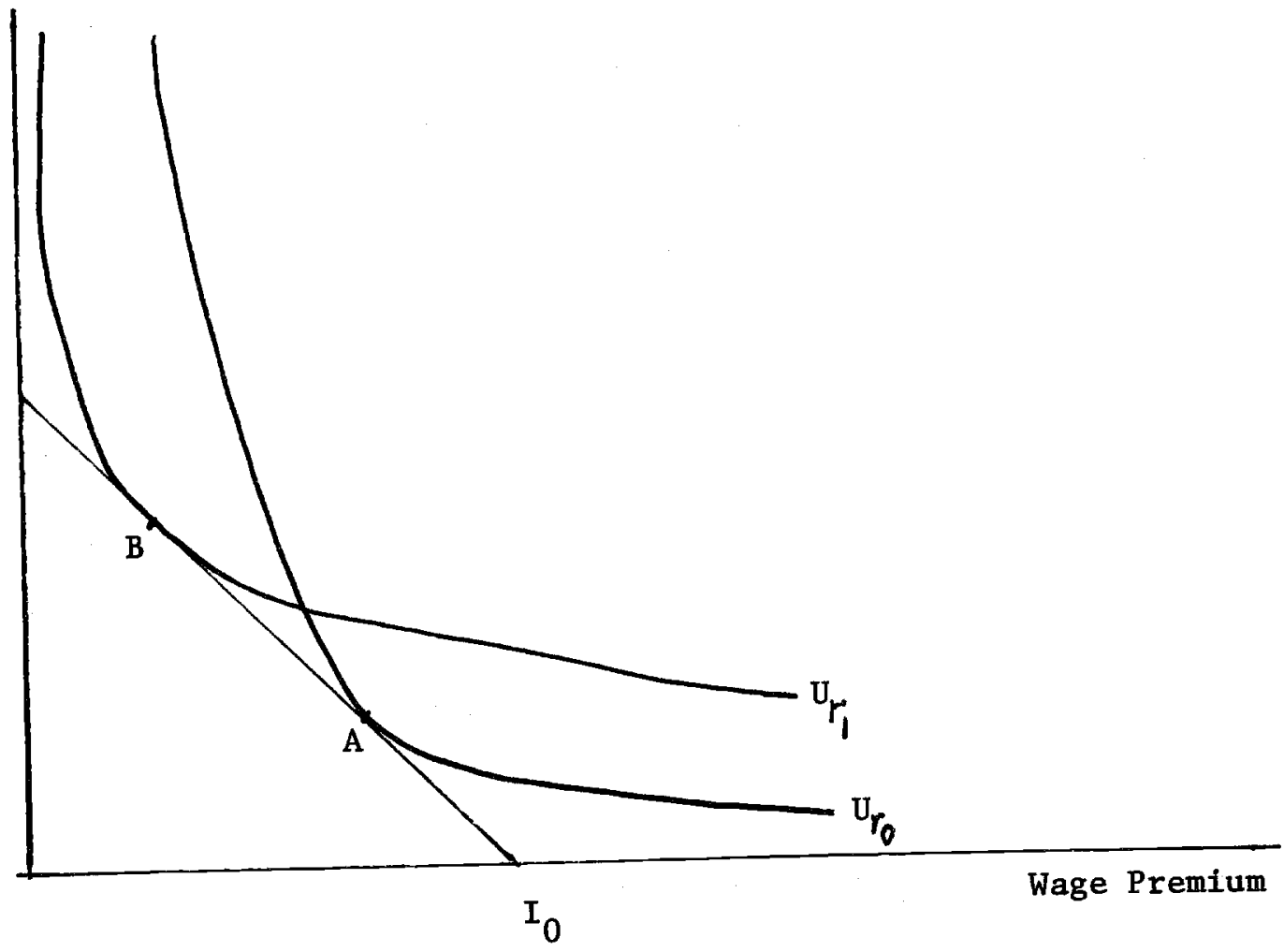

Figure 1. Optimal Wage-Indexing Under Changing Uncertainty 
employer, the best combinations of indexation and risk premiums that are consistent with obtaining workers are shown by the isoutility of profits curve $I_{0}$ in Figure 1. Lower curves are more desirable to the employer. The curves slope downward: Larger premiums obviously reduce profits, while greater indexation reduces profits if it is associated with more frequent, costly wage adjustments.

One of the effects of increased uncertainty may be to decrease the correlation workers perceive between $p$ and $y_{i}$. The lowered correlation, to $r_{1}$, causes the utility frontier $U$ in Figure 1 to become flatter at any combination of indexation and wage premium. So long as workers are risk averse, the increased uncertainty reduces their willingness to trade off indexed wages which protect their purchasing power for additional contingent risk premiums.

The typical worker's utility frontier rotates to $\mathrm{U}_{\mathrm{r}_{1}}$. Assuming product markets are competitive and employers are risk neutral, the optimal contract moves to point $B$, with a greater reliance on indexing and lessened reliance on payments based on conditions in the individual product market. $2 /$ This change implies that $\gamma$ in equation ( $\left.1^{\prime}\right)$ will increase and $\alpha$ decrease as the extent of uncertainty rises.

\section{Summary of Implications}

The two approaches carry specific and contrasting implications for the effects of inflation on the variance of relative wage changes. These are summarized in Table 1 . Absent any good definition of what uncertainty about inflation means, we assume that unexpected inflation is one proxy for the extent of that uncertainty; another is discussed in Section III. If we make this assumption, the implications of contracting for the 
variance of relative wage changes are quite different from those of the hypotheses involving some form of wage rigidity. Thus an examination of the effect of price inflation on the dispersion of wage changes provides evidence on whether inflation does aid labor markets to work more efficiently.

Table 1. Summary of Hypotheses

$$
\begin{array}{r}
\operatorname{Var}_{i} \\
\text { Effect of: } \quad p^{e} \quad p^{u}
\end{array}
$$

1. a. Nominal Wage Rigidity

b. Ex ante Real Wage Rigidity

\section{Contracting}

III. The Variability of Relative Wage Changes

To capture expectations about inflation I use the Livingston survey of economists, most of whom were in private industry (Carlson, 1977); the Survey Research Center survey of a random sample of households (JusterComment, 1980); and ARMA forecasts of inflation. The Livingston surveys are taken semiannually in June and December, when information about the CPI through April and October respectively is available. Accordingly, I let each observation be a half year, January-June and July-December. $p^{e}$ for the first (second) half year is the average from the Livingston survey in the previous December (June). $p^{u}$ is the difference between actual inflation and $p^{e}$. The Livingston survey asks questions about expectations of inflation over the next six and twelve months. I use both sets of data, and compute the $\mathrm{p}^{\mathrm{u}}$ corresponding to each series by taking the most recent six or twelve months of changes in the CPI. Thus, for example, the observation on $\mathrm{p}^{\mathrm{u}}$ for the second half of 1981 
using six-month inflation expectations is the difference between the annualized rate of change in the CPI between April 1981 and October 1981, and the June 1981 average response in the Livingston survey.

The SRC data were collected quarterly through 1979, monthly since then. I use the second and the fourth quarters' observations to correspond to the June and December data from the Livingston survey before 1980, and use the May and November data for 1980 and 1981. Inflationary expectations are also calculated based on continuously-updated forecasts from an ARMA $(5,1)$ process. $\underline{3} /$

It is unclear what are the appropriate proxy variables for greater uncertainty about inflation. Lacking any theory of what is a good measure of this type of uncertainty, I experiment with alternative proxies. Included among these are $\mathrm{p}^{\mathrm{u}}$ and the variances among the respondents in the Livingston and the SRC surveys of the estimates of the rate of inflation.

Equation (6) suggests that a measure of the dispersion of changes in output across sectors be included along with measures of inflation or inflation uncertainty as independent variables in estimating equations describing the variance in relative wage changes. Expecting that periods of incomes policy would produce reductions in the inequality of relative wage changes, I also add dummy variables for the period of the Kennedy-Johnson wage-price guideposts and the Nixon controls to these equations. Since the latter were statistically insignificant and did not affect the other parameter estimates, they were deleted from the equations. The guidepost variable, G, takes the value one from 1962 through the first half of 1966 . The basic equation to be estimated is:

(7) $\log \left(\operatorname{Var} w_{t}\right)=\beta_{0}+\beta_{1} p_{t}^{e}+\beta_{2} p_{t}^{u}+\beta_{3} \log \left(\operatorname{Var} y_{t}\right)+\beta_{4} G_{t}+\varepsilon_{t}$, 
where $\varepsilon_{t}$ is a disturbance term.

The equations to be estimated in this section are based on two different sets of data. The first covers most of the private nonfarm economy. The seven sectors are construction and mining; finance, insurance and real estate; services; wholesale and retail trade; transportation and public utilities; durable manufacturing, and nondurable manufacturing. $4 /$ Except for the two manufacturing sectors, the data on hourly earnings needed to construct $\operatorname{Var} w_{i}$ are only available since 1964 ; thus the estimated equations cover 1965-1981 only. Var $w_{t}$ is calculated as:

$$
\operatorname{var} w_{t}=\sum_{i}\left(\frac{w_{i t}}{w_{i t-2}}-1\right)^{2} E_{i t} \text {, }
$$

where $W_{i}$ is the ratio of average hourly earnings (adjusted for overtime) in sector $i$ to a weighted average of earnings among the seven sectors, and $E_{i t}$ is the $i^{\text {'th }}$ sector's share of total employment of production workers at time $t$. The series on $\operatorname{Var} w_{t}$ is shown in the first column of Table 2; there is no obvious trend in it. Var $y_{t}$ is constructed analogously using data on nominal national income by sector deflated by an appropriate price index. $\underline{5}$

The second data set covers twenty two-digit manufacturing industries (a11 of manufacturing except ordinance) for 1955-81. Var $w_{t}$ is calculated as in (8), based on the average hourly earnings of production workers by industry. The series is 1isted in column (2) of Table 2; like Var $w_{t}$ for the private nonfarm economy, it too shows no particular trend. The variance of changes in output is an employment-weighted average of changes in the Federal Reserve Board's index of industrial production. All the models are estimated using the maximum likelihood method of adjusting for serially 
correlated errors proposed by Beach and Mackinnon (1978).

Table 3 presents the estimates of equations describing $\log \left(\operatorname{Var} \mathrm{w}_{t}\right.$ ) for the private nonfarm economy; Table 4 presents the same equations estimated for manufacturing. In each table columns (1)-(3) list parameter estimates based on six-month inflation rates and the Livingston six-month inflation forecasts; columns (4)-(6) list estimates using twelve-month Livingston forecasts and price changes; columns (7) and (8) use the SRC data, and columns (9) use the ARMA forecasts. Comparing the estimates in column (1) in each table to those in column (2) (or the estimates in column (4) to those in columns (5), (7) and (9)), one sees clearly that, no matter which sectors, price expectations or inflation horizon is used, accounting for inflationary expectations improves the ability to track variations in the dispersion of relative wage changes. The adjusted $\overline{\mathrm{R}}^{2}$ is greater in each equation that decomposes price inflation into expected and unexpected components. Actual inflation alone reduces dispersion in both samples, though not significantly so in the data from manufacturing. If one ignores inflationary expectations, though, one would fail to capture the mechanism through which inflation affects the dispersion of wage changes.

The most important findings are contained in columns (2), (5), (7) and (9) of each table. In each sample, for each inflation horizon and for each series on price expectations unexpected price inflation produces a significant negative effect on the dispersion of wage changes. Expected inflation has no significant impact on dispersion except for the ARMA forecasts in Table 3 (though the coefficients on $\mathrm{p}^{\mathrm{u}}$ and $\mathrm{p}$ are different from each other fairly at low levels of significance--1.9>/t/>1.2). Both results accord fully with the implications of the contracting hypothesis outlined in Section II, assuming uncertainty about inflation is related 

Table 2. Variance of Relative Wage Changes, Semiannually

(1)

(2)

(1)

(2)

\begin{tabular}{|c|c|c|c|c|c|}
\hline Year & $\begin{array}{c}\text { Private Nonfarm } \\
\text { Industry }\end{array}$ & Manufacturing & Year & $\begin{array}{c}\text { Private Nonfarm } \\
\text { Industry }\end{array}$ & Manufacturing \\
\hline \multirow[t]{2}{*}{1955} & & 2.79 & 1970 & .70 & 1.32 \\
\hline & & 3.38 & & 1.18 & 2.08 \\
\hline \multirow[t]{2}{*}{1956} & & 2.06 & 1971 & .84 & 2.35 \\
\hline & & 1.94 & & 1.04 & 2.13 \\
\hline 1957 & & .86 & 1972 & 1.95 & 2.18 \\
\hline \multirow[t]{2}{*}{1958} & & 1.71 & & 1.62 & 1.73 \\
\hline & & 2.08 & 1973 & .49 & .87 \\
\hline \multirow[t]{2}{*}{1959} & & $\begin{array}{l}2.62 \\
2.77\end{array}$ & & .25 & 1.12 \\
\hline & & $\begin{array}{l}2.77 \\
1.87\end{array}$ & 1974 & $\begin{array}{r}.24 \\
35\end{array}$ & 1.13 \\
\hline \multirow[t]{2}{*}{1960} & & $\begin{array}{l}1.87 \\
1.04\end{array}$ & 1975 & $\begin{array}{r}.35 \\
1.01\end{array}$ & 1.34 \\
\hline & & $\begin{array}{r}1.04 \\
.73\end{array}$ & & $\begin{array}{r}1.01 \\
.72\end{array}$ & $\begin{array}{l}2.16 \\
2.77\end{array}$ \\
\hline \multirow[t]{2}{*}{1961} & & 1.03 & 1976 & $\begin{array}{r}.72 \\
1.62\end{array}$ & $\begin{array}{l}2.77 \\
2.80\end{array}$ \\
\hline & & .81 & & .52 & $\begin{array}{l}2.80 \\
1.07\end{array}$ \\
\hline \multirow[t]{2}{*}{1962} & & .51 & 1977 & .38 & $\begin{array}{l}1.07 \\
1.78\end{array}$ \\
\hline & & .81 & & .85 & $\begin{array}{l}1.78 \\
1.44\end{array}$ \\
\hline \multirow[t]{2}{*}{1963} & & .57 & 1978 & .59 & $\begin{array}{l}1.44 \\
1.40\end{array}$ \\
\hline & & .35 & & .51 & $\begin{array}{r}1.40 \\
.80\end{array}$ \\
\hline \multirow[t]{2}{*}{1964} & & .72 & 1979 & .60 & $\begin{array}{l}.80 \\
.78\end{array}$ \\
\hline & & .34 & & .22 & $\begin{array}{l}.78 \\
.50\end{array}$ \\
\hline 1965 & .35 & .45 & 1980 & .40 & $\begin{array}{r}.50 \\
1.11\end{array}$ \\
\hline \multirow{2}{*}{1966} & .34 & .65 & & .30 & $\begin{array}{l}1.11 \\
1.00\end{array}$ \\
\hline & 1.02 & .49 & 1981 & .60 & $\begin{array}{l}1.00 \\
1.65\end{array}$ \\
\hline \multirow{2}{*}{1967} & 2.21 & .50 & & .42 & $\begin{array}{r}1.65 \\
.75\end{array}$ \\
\hline & .61 & 1.75 & & & \\
\hline \multirow{2}{*}{1968} & .43 & 2.00 & & & \\
\hline & .40 & 1.43 & & & \\
\hline \multirow{3}{*}{1969} & .20 & 1.10 & & & \\
\hline & .40 & .12 & & & \\
\hline & .65 & .86 & & & \\
\hline
\end{tabular}

âa/ Each variance in this Table has been multiplied by $10^{4}$. 


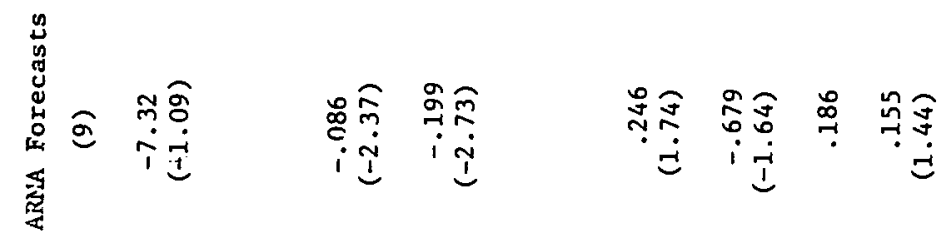

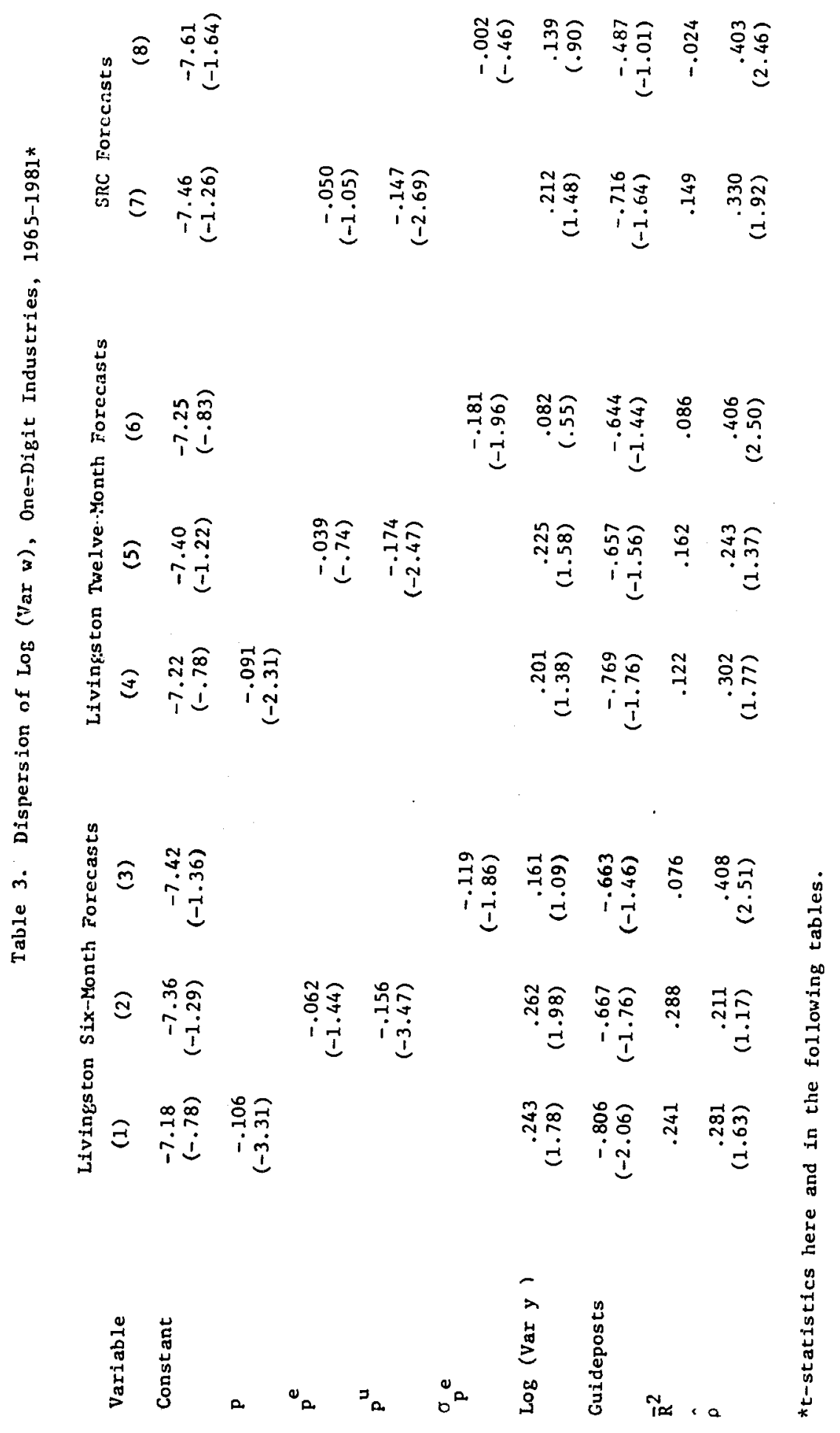


产
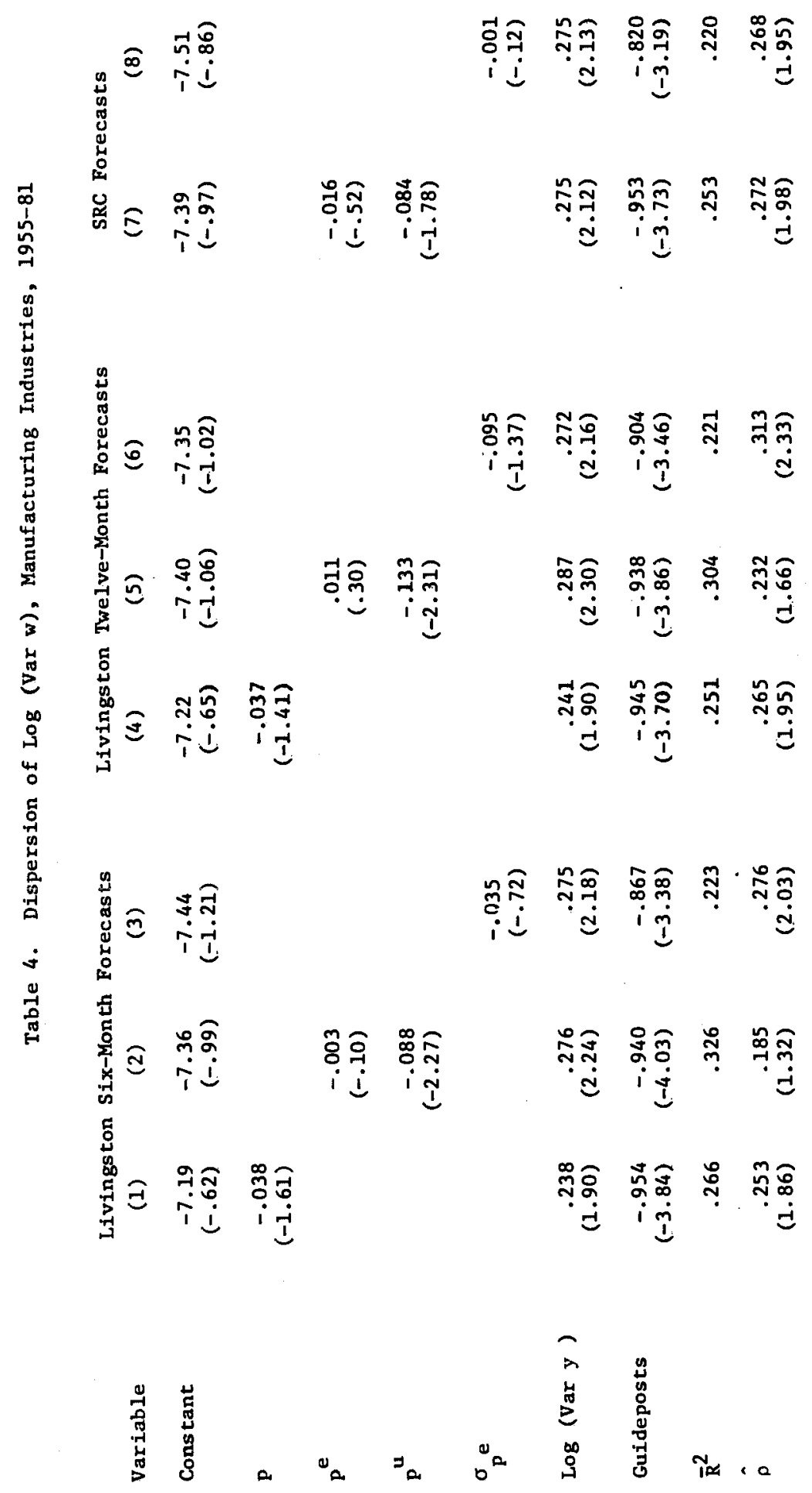
to unexpected inflation. The negative effect of $\mathrm{p}^{\mathrm{u}}$ sharply contradicts the notion that inflation allows wage changes to reflect real factors more closely: More rapid price inflation compresses wage changes. Perhaps the only support for the hypothesis of downward nominal or ex ante real wage rigidity is that the impact of $\mathrm{p}^{\mathrm{e}}$ is more positive than that of $\mathrm{p}^{\mathrm{u}}$. Since the latter's impact is negative, and since $\mathrm{p}^{\mathrm{e}}$ has no effect, this is awfully weak support. It seems fair to conclude that, though the results do not (indeed, could not) disprove the existence of downward nominal or ex ante real wage rigidity, they suggest very strongly that such rigidity describes wage-setting since the 1950 s in the United States very badly.

Estimates of the equations describing the log variance of relative wage changes that include measures of the dispersion of forecasts of inflation are presented in columns (3), (6) and (8) of Tables 3 and 4. Only in those equations for manufacturing industries in which the Livingston expectations data are used does the variance of inflation forecasts induce a significant reduction in the dispersion of relative wage changes (though the coefficients are negative in the other four cases). $6 /$ while providing some support for the contracting hypothesis, these equations clearly are less successful than those that include the actual rate of inflation or its decomposition into expected and unexpected inflation. Given the difficulty of identifying proxies for uncertainty about inflation, one might infer that both sets of results support the contracting hypothesis.

The results on the effect of expected and unexpected inflation stand in sharp contrast to those in the literature that examines the role inflation plays in affecting variation in relative prices. As Parks (1978) has shown for relative price variation, I have shown that 
variation in relative wage changes is unaffected by anticipated inflation. The dispersion diminishes with unexpected inflation in prices, while the literature suggests relative price variability increases with unexpected inflation. The diminution in relative wage increases can be viewed as a reduction in the ability of relative wages to reflect yariations in the relative demand for labor by sector. Thus, following Friedman's (1977) argument that inflation reduces the ability of relative prices to function as allocative signals, the results here suggest that it does so by compressing relative variation (in this case, relative wage variation) rather than by widening it. That studies of relative price variation fail to find this compression may be due to misspecification--their failure to include measures of variation in the relative demand for commodities.

An increase in the variance of changes in output produces the expected positive effect on the dispersion of relative wage changes. This impact is significantly positive for nearly all formulations of the estimating equation and data sets. It implies that the failure to include changes in relative demand when examining the effect of price inflation on the dispersion of wage (or price) changes will produce an incomplete description of the underlying process. The other variable in the equations, a dumny for the Kennedy-Johnson wage-price guideposts, sharply reduced the variability of wage changes. The reductions were roughly 50 percent from the rest of 1965-81 in the private nonfarm sector, and were 60 percent in manufacturing from the rest of 1955-81. That the reduction was greater within manufacturing than within the nonfarm sector is consistent with the guideposts! focus on . the larger firms in manufacturing.

A number of alternative specifications of the equations in Tables 3 and 4 were estimated, each embodying some alternative variable correlated 
Table 5. Dispersion of Relative Wage Changes, One-Digit Industries, 1965-1973:1, 1973:2-1981

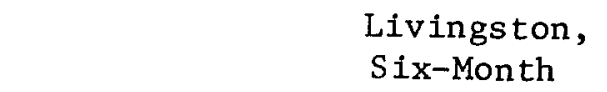

Variable

(1)

Livingston, Twelve-Month

(2)

$$
p^{e}
$$

.006
$(.02)$

$\mathrm{p}^{\mathrm{u}}$

$\overline{\mathrm{R}}^{2}$

$-.084$

$(-.63)$

$-.149$

\section{5-1973:1}
.086
$(.24)$
$-.018$
$(-.09)$
$-.179$

Survey Research Center

ARMA

(3)

(4)
$-.017$
$(-.07)$

.027

.016

(.08)

(.14)

$-.183$

$-.045$

$(-.20)$

$-.174$

$1973: 2-1981$

$$
\begin{aligned}
& p^{e} \\
& p^{u}
\end{aligned}
$$$$
.004
$$$$
\text { (.06) }
$$$$
.062
$$$$
\text { (.87) }
$$$$
-.023
$$$$
\text { (-.39) }
$$$$
-.066
$$$$
-.205
$$$$
-.161
$$$$
(-3.39)
$$

$-.156$

$(-2.51)$

$(-4 \cdot 12)$

.369

.279

$-.215$

.527

$(-2.68)$

.479 
Table 6. Dispersion of Relative Wage Changes, Manufacturing Industries, 1955-1973:1, 1973:2-1981

Livings ton, Six-Month

Variable

(1)

Livingston, Twelve-Month

(2)

$1955: 1-1973: 1$

$p^{e}$

$p^{u}$

$\overline{\mathrm{R}}^{2}$

$-.031$

$(-.30)$

$-.124$

$(-1.79)$

.311
$-.042$

$(-.41)$

$-.219$

$(-2.12)$

.303

\section{Survey Research} Center

(3)
(4)

ARMA 
with unexpected inflation and thus perhaps accounting for the surprising results obtained here. For example, one might expect that more widespread unionization would reduce the variation in relative wage increases, as union wage bargains focus less on labor-market conditions than does nonunion wagesetting. I/ A measure of the fraction of the work force unionized did not affect the coefficients on the inflation terms in the equations, nor did the extent of unionism affect relative wage variability. Similarly, a greater prevalence of indexed labor contracts might be expected to account partly for our results, because more rapid inflation leads to greater indexation. $8 /$ However, when the fraction of the work force covered by cost-of-living escalators was included, only a slight reduction in the estimated impact of unexpected inflation occurred. $9 /$ The results in Tables 3 and 4 are also robust to the inclusion of the rate of change of an index of average wage increases. This should increase one's confidence in the results as reflections of increased indexing, rather than as partial reflections of other conditions in the labor market. A catch-all time trend was also added to the equations; it too had little effect on the estimated effects of inflation, nor was the trend itself significant. 10 /

The structure of most industrial economies was sharply affected by the rise in energy prices in the early 1970s, as indicated by a temporary increase in the extent of structural unemployment (Lilien, 1982). This important change may be accounting for our results: The reduced variability of relative wage changes that we have shown is associated with more rapid inflation may be a reflection of the simultaneous rapid change in relative factor prices instead. To examine this the basic equation was reestimated for the semiannual periods through the first half of 1973, and from the second half of 1973 through 1981. Parameter estimates of the variables of 
interest in (8) are presented in Tables 5 and 6.

As the Tables show, even during the post-OPEC period unexpected inflation reduced the variability of relative wages. Anticipated inflation had little effect on the dispersion of relative wage changes in the data for the private nonfarm sector, but did have significant effects on dispersion within manufacturing. The results for the period before 1973 are very weak for the private nonfarm sector, perhaps because of the narrow range of observations on rates of anticipated and unanticipated inflation between 1965 and 1973. For manufacturing, on which a longer time series of data are available, the results for the first subperiod are qualitatively similar to those in Table 4. Indeed, despite the apparent differences in some of the coefficients between the subperiods, we cannot reject any of the hypotheses about pooling the data for these subperiods. 11/

Table 7 presents the means and extreme values of the series on price inflation (expected and unexpected). The ranges of $\mathrm{p}^{\mathrm{u}}$ are quite large. Applying them to the estimated responses of the dispersion of relative wage changes demonstrates that they produce effects that are substantial as well as significant. In the private nontarm sector the dispersion was between 61 and 68 percent lower (depending upon the equation used) at the peak rate of unexpected inflation compared to the lowest rate; in manufacturing the comparable range of effects is between 42 and 54 percent.

\section{v. Conclusions}

This study demonstrates the existence of a striking relation of the response of labor markets to price inflation. The variability of relative wage changes decreases when price inflation accelerates. The decrease is mainly a response to unanticipated inflation; anticipated inflation has little impact on the dispersion of changes in relative wages. The results are quite robust with respect to changes in the sample period, the measures 
Table 7. Descriptive Statistics, $\mathrm{p}^{\mathrm{u}}, \mathrm{p}^{\mathrm{e}}, 1955-1981$

Period $\quad$ Mean $\begin{gathered}\text { 1965-1981 } \\ \text { Minimum }\end{gathered}$ Maximum $^{a} \quad \begin{gathered}\text { 1955-1981 } \\ \text { Mean Minimum }\end{gathered}$

\section{Data}

Livingston, 6-month

$\begin{array}{lrrrrr}\mathrm{p}^{\mathrm{u}} & 1.89 & -1.42 & 5.92 & 1.49 & -1.42 \\ \mathrm{p}^{\mathrm{e}} & 4.87 & .94 & 10.68 & 3.33 & .07\end{array}$

Livingston, 12-month

$\begin{array}{lrrrrr}\mathrm{P}^{\mathrm{u}} & 1.66 & -.66 & 5.17 & 1.29 & -.66 \\ \mathrm{P} & 4.96 & 1.07 & 10.27 & 3.42 & .00\end{array}$

Survey Research Center

$\begin{array}{rrrrrr}\mathrm{p}^{\mathrm{u}} & .66 & -1.85 & 4.54 & .45 & -1.85 \\ \mathrm{p}^{\mathrm{e}} & 5.96 & 2.52 & 11.40 & 4.27 & -.24\end{array}$

ARMA

$\begin{array}{lrrrrr}\mathrm{p}^{\mathrm{u}} & .20 & -3.99 & 1.98 & .23 & -3.99 \\ \mathrm{p}^{\mathrm{e}} & 6.41 & .93 & 15.36 & 4.49 & -.18\end{array}$

${ }^{a}$ The maximum values for $1955-1981$ are identical to these, except that $\max \left(p^{u}\right)$
for the ARMA forecasts was 2.30 . 
of anticipated and unanticipated inflation, and the choice of sectors over which the measures of dispersion are calculated.

The negative relation between unexpected inflation and the dispersion of relative wage changes is quite inconsistent with the notion that inflation allows labor markets to work more smoothly by ameliorating the impact of downward nominal wage rigidity. Rather, the finding can be interpreted as implying that unexpected inflation reduces the responsiveness of relative wages to changes in real factors. This implies that unexpected inflation hinders the ability of wages to allocate labor among industries in response to changes in relative demands. The finding is consistent with the role of increased uncertainty affecting workers' desires to minimize risk in implicit wage contracts. It is also consistent with workers entering the labormarket in response to unanticipated increases in nominal wages (Lucas-Rapping, 1969) and supplying their labor to industries where demand is growing most rapidly and thus where relative wages would be rising most rapidly if the size of the labor force remained unchanged). $\underline{12 /}$

Inflation does not have the desirable side-effect of enabling employers to restructure relative wages more rapidiy than otherwise in order to reflect changes in relative demand. Quite the contrary: Relative wage rigidity is increased by inflation. We have attributed this to workers' seeking to reduce fluctuations in their purchasing power by linking wage increases more closely to aggregate price changes than to changes in excess demand in their industry. The increase suggests that one cannot point to the labor market as a sector of the economy whose functioning is improved by price inflation. 


\section{REFERENCES}

J. Altonji, "The Intertemporal Substitution Model of Labor Market Fluctuations: An Empirical Analysis," Review of Economic Studies, 49(1982), 785-824.

0 . Ashenfelter and R. Layard," Incomes Policy and Wage Differentials," Economica, 50 (May 1983).

C. Azariadis, "Implicit Contracts and Underemployment Equilibria," Journal of Political Economy, 83 (December 1975), 1183-1202.

C. Beach and J. MacKinnon, "A Maximum Likelihood Procedure for Regression with Autocorrelated Errors," Econometrica, 46 (January 1978), 51-58. J. Brown, "How Close to an Auction is the Labor Market?," Research in Labor
Economics, 5 (1982), 189-235.

J. Carlson, "A Study of Price Forecasts," Annals of Economic and Social Measurement, 6 (Winter 1977), 27-56.

A Cukierman and P. Wachtel, "Relative Price Variability and Nonuniform Inflationary Expectations," Journal of Political Economy, 90 (February 1982), 146-157.

S. Fischer, "Relative Price Variability and Inflation in the United States and Germany," European Economic Review 18 (May/June 1982), 171-196.

M. Friedman, "Nobel Lecture: Inflation and Unemployment," Journal of Political Economy, 85 (June 1977), 451-472.

J. Gray, "On Indexation and Contract Length," Journal of Political Economy 86 (February 1978), 1-18.

D. Hamermesh, "Wage Bargains, Threshold Effects and the Phillips Curve," Quarterly Journal of Economics, 84 (August 1970), 501-517.

F. T. Juster and R. Comment, "A Note on the Measurement of Price Expectations," Unpublished Paper, University of Michigan Institute for Social Research,
1980. D. Lilien, "Sectoral Shifts and Cyclical Unemployment," Journal of Political
Economy, 90 (1982), 777-793.

R. E. Lucas and L. Rapping, "Real Wages, Employment and Inflation," Journal of Political Economy, 77 (September/October 1969), 721-754.

T. MaCurdy, "An Empirical Model of Labor Supply in a Life-Cycle Setting," Journal of Political Economy 89 (1981), 1059-1085.

R. Parks, "Inflation and Relative Price Variability," Journal of Political Economy, 86 (February 1978), 79-95. 
A. Rees, "The Phillips Curve as a Menu for Policy Choice," Economica, 37 (August 1970), 227-238.

J. Sachs, "Wages, Profits, and Macroeconomic Admustment: A Comparative Study," Brookings Papers on Economic Activity (1979), 269-319.

J. Tobin, "Inflation and Unemployment," American Economic Review, 62 (March 1972), 1-18.

D. Vining and T. Elwertowski, "The Relationship Between Relative Prices and the General Price Leve1," American Economic Review, 66 (September 1976), 699-708.

M. Wachter, "Cyclical Variation in the Interindustry Wage Structure," American Economic Review, 60 (March 1970), 75-84. 
FOOTNOTES

1. Sachs (1979) presents evidence on the importance of real wage rigidity during the 1970s in a number of industrialized countries.

2. The assumption of risk-averse workers and risk-neutral firms has been used in the contracting literature by, among others, Azariadis (1975). So long as the degree of relative risk aversion among workers exceeds that among employers, the result in the text will hold.

3. This process implies $2-1 / 2$ years of lagged terms. Experiments with longer lags never yielded higher $\overline{\mathrm{R}}^{2}$. 4. The data used to calculate Var $w_{t}$ and Var $y_{t}$ are taken from the CITIBASE
data file.

5. To deflate the nominal flows of national income by sector, I use: For construction and mining, the implicit price deflator for private nonresidential structures; for services, and for finance, etc., the CPI-U for services, excluding rent; for wholesale and retail trade, the producer price index for all commodities; for transportation and public utilities, the implicit price deflator for personal consumption expenditures on transportation; and for manufacturing, durable and nondurable, the respective implicit price deflators for personal consumption expenditures.

6. Including $\sigma_{p} e$ in the equations in columns (2), (5) and (7) in Tables 3 and 4 changes ${ }^{p}$ the results little. The significance of the terms in $\mathrm{p}$ decreases very slightly; that of $p$ declines even further below what is shown in the Tables; and the dispersion of expected inflation itself produces the same negative, though generally insignificant effect on the logarithm of the dispersion of relative wage changes.

7. Relatively greater reliance on price changes than on unemployment in wage-setting in unionized industries is demonstrated by, among others, Hamermesh (1970).

8. Between 1957 and 1981 the fraction of workers in the U.S. who were covered by a negotiated cost-of-living clause ranged from .027 to .069 . The highest values occurred in 1958-1959, and in 1975-1977; both are periods that followed an acceleration in the rate of inflation.

9. The small effects on the parameter estimates do not contradict the implications of our application of contracting to the determination of relative wage changes. Only a tiny fraction of workers are covered by formal indexation. Our argument and, indeed, the whole contracting literature applies to implicit arrangements. Thus the most one can do by accounting for the fraction of workers covered by escalator clauses is to limit the data to the overwhelming majority of the work force whose wages may be affected by implicit contracting. 
10. Also, tests of Granger and Sims causality in each sample and for each measure of pu could not reject the hypothesis that it is exogenous in the equations presented in Tables 3 and 4.

11. None of the F-statistics testing the correctness of pooling exceeds 1.6 , and most are below one. With the degrees of freedom implied by the sample size and the number of regressors, none comes anywhere near to being significant at even the 10 percent level.

12. While this is possible, the underlying requirement--that workers supply labor elastically in response to transitory changes in perceived real wages-is not supported by the data (see MaCurdy, 1981). 